Research Article

\title{
Open Innovation Mode of Green Innovation System for Manufacturing Industry
}

\author{
Shao Bo ${ }^{1}$ and Bi Kexin (iD ${ }^{1,2}$ \\ ${ }^{1}$ School of Economics and Management, Harbin University of Science and Technology, Harbin 150080, China \\ ${ }^{2}$ School of Economics and Management, Harbin Engineering University, Harbin 150080, China \\ Correspondence should be addressed to Bi Kexin; xuanfeng@hrbust.edu.cn
}

Received 7 March 2021; Revised 28 March 2021; Accepted 18 June 2021; Published 28 June 2021

Academic Editor: Mian Ahmad Jan

Copyright (C) 2021 Shao Bo and Bi Kexin. This is an open access article distributed under the Creative Commons Attribution License, which permits unrestricted use, distribution, and reproduction in any medium, provided the original work is properly cited.

\begin{abstract}
The open mode of the manufacturing innovation system under conventional conditions makes it difficult to realize the open operation of the green innovation system, which also lacks operational capability and has low analysis coverage. Therefore, an open model of the green innovation system in the manufacturing industry is put forward. The opening and functional elements of the model are determined. The mechanism of the environmental aspects is clarified. The adaptability of different levels of the innovation process is discussed, and its evolution theory is derived. Finally, the best open innovation model's selection rules are chosen to realize the analysis of the open innovation model's mechanism. Its established operational index and model mechanism are discovered for the manufacturing industry. The experimental data show that our proposed model of the green innovation system is more efficient than the conventional model as its operational ability is increased by $33.42 \%$, and the coverage rate is enhanced by $54.32 \%$.
\end{abstract}

\section{Introduction}

The open mode of the manufacturing industry's innovation system (under the conventional conditions) aims to provide services only to the manufacturing enterprises. Because of the restrictions imposed on the structure itself, it is challenging to realize the open, innovative operation of the green innovation system. Besides, there is a shortage of poor operational ability and low analysis coverage [1]. Therefore, green innovation of the manufacturing industry under the Internet is proposed. Based on the Internet conditions, the main elements of enterprises, governments, universities, and intermediaries are analyzed, and the internal relationships are established according to Oswald's market innovation theory [2]. The functional elements of knowledge development and knowledge diffusion are clarified, the available subjects of universities and governments are determined, and the natural environment, resources, and infrastructure are clearly defined. Green computing has a vibrant range of meanings, including power saving. It is also necessary to build a green manufacturing industry and play an essential role in constructing smart cities [3].

This study expounds on the open innovation evolution theory. It sets up the information selection rules of the open innovation mode by using the best choice of different subjects' internal or external elements to realize the open innovation model machine [4]. Based on the open innovation mechanism, we built our model, and the related indexes such as aggregation, nonlinearity, and diversity are determined $[5,6]$. To ensure our open innovation model's effectiveness, the manufacturing industry's experimental environment is simulated. The operational capability and the analysis coverage simulation test are carried out using two open innovation models [7]. In [8], the authors studied the open innovation mode based on the Internet platform. They found that it is composed of the external system and internal system. The external system includes environment, policy, and technology. The internal system is strategy, value, incentive, and feedback. The internal and external systems work together to realize the open innovation mode. In [9], the authors 
proposed that open innovation breaks enterprises' boundaries by interconnecting internal resources and external resources, continuously injects innovative ideas into enterprises, and improves enterprises' innovation levels. In [10], the authors used a case study to analyze the open innovation mode of Shenyang Machine Tool Co., Ltd. They found that its open innovation mode aims to achieve intelligent manufacturing, based on the Internet platform. Combined with the enterprise's internal management system, it promotes the development of enterprise's innovation level.

Till date, numerous studies have been conducted on industrial innovation applications, green innovation system, and open innovation mode. However, it can be found that the research of the open innovation mode mostly focuses on the manufacturing enterprise level. It rarely involves the industry level or the open innovation mode of the green innovation system. The research of the green innovation system mainly focuses on the construction and function of the enterprise's green innovation system, and the open innovation mode is the open innovation mode for the enterprise. Research on the impact and evaluation of innovation performance is less about the open innovation mode of industry and the innovation mode of the green innovation system. The conclusion of this paper can also enrich the academic research results in related research fields. The main contributions of this work are as follows.

(1) We suggest the selection of the open innovation mode for the industrial green innovation system. It starts from the resource theory and demand life cycle theory. It is considered that the specific requirements of the open innovation mode for the industrial green innovation system at different development stages are also different. Therefore, according to the specific analysis of the development stage of the green innovation system, it is necessary to select the open innovation mode suitable for the development stage innovative mode.

(2) The simulation model research results are more convincing. In this paper, the system dynamics model's test method is used to analyze the industrial green innovation system, and then, according to the software operation results, the future operation trend of the industrial green innovation system is evaluated. At the same time, according to the changes of the variables in the system, the simulation time period of the industrial green innovation system is divided into four development stages, and the simulation time is divided into four stages. Each stage of development has its own characteristics.

The rest of this paper is organized as follows. In Section 2 , the establishment of an open innovation mode for the green innovation system in manufacturing industry is discussed. In Section 3, an analysis of the open innovation model is provided. In Section 4, the construction mechanism for an open innovation model is provided. In Section 5, experimental results are provided for our model. Finally, we conclude this paper in Section 6.

\section{The Establishment of Open Innovation Mode for Green Innovation System in Manufacturing Industry}

Elements are the basic components of the open innovation model of the green innovation system in the manufacturing industry [11]. This paper divides them into three main parts: main elements, functional elements, and environmental elements based on Internet conditions' advantages. The functional elements are the pioneering activities of green innovation, knowledge development (learning), knowledge diffusion, research orientation, market formation, resource flow, creation of legitimacy, and resistance to change. The environmental elements include the material environment (including the natural environment, resource environment, and infrastructure) and soft environment (including institutional environment, market environment, and cultural environment). There is a linkage between the main body, function, and environmental elements [12].

2.1. Determination of the Open Elements of the Subject. In the open mode of the innovation system, enterprises are the core body, which play a vital role. The enterprises directly face the market, first understand the market demand, and make the feedback in time. Its market reflection ability, information feedback ability, and green technology innovation ability play a key role in the operation of the whole green innovation system. According to Oswald's market innovation theory, the role of enterprises in the green innovation system can be expressed using the following equation:

$$
\text { antcb }=\frac{\sum_{i=1}^{n} k H \cdot t}{C+F} .
$$

In this equation, antcb represents the function element of the enterprise in the innovation system, $k$ represents the market randomness, $n$ represents the number of active enterprises in the market, $C$ represents the reaction ability of the market, $F$ represents the green innovation technical ability, and $H$ represents the market feedback capability.

The relationship between the enterprises will help to form the scale of the industry, enhance the overall competitiveness of a single enterprise, and promote the development of the green innovation system of the whole manufacturing industry. School-enterprise cooperation is conducive to increasing the cooperative relationship between schools and enterprises [13]. It will increase knowledge accumulation and provide intellectual support for enterprises [14]. Moreover, cooperation between enterprises 
and intermediaries is conducive to the smooth communication and connection between enterprises and internal bodies of the green innovation system, which build a key bridge between the enterprises and the various subjects [14]. Freeman pointed out that the role of the government in green innovation can be expressed using the following equation [15]:

$$
F=\left[\frac{G-g V}{v_{\max }}, \frac{G-g V}{v_{\max }}\right] .
$$

In this equation, $F$ represents the government's influence on the green innovation subject, $G$ represents the relevant policies formulated by the government, $V$ represents the implementation of the policy, $g$ represents the external elements, and $v$ represents the feasibility [16].

The role of the government in the green innovation system of manufacturing industry has two sides [17]. On the one hand, it is a participant in the green innovation system, which plays the role of making various policies and regulating the laws and implementing them within the system. On the other hand, the government is the macroregulator of the whole green innovation system. It is necessary to rationally configure the resources within the whole system and guide the behavior of the main body [18].

Universities and research institutes provide knowledge sources for the green innovation system of the whole manufacturing industry. Institutions of higher learning and scientific research institutes are determined by their own attributes so that they can concentrate on the research and development of green technology. They often do not worry too much about market risk or market value. It is easier to develop a breakthrough technology with high market value and high technology content than the enterprises [19].

On the contrary, universities and scientific research institutes also carry out the cultivation of green creative talents. Talent is the carrier of knowledge. Many green innovation talents pour into the market, enrich the knowledge base of the green innovation system, and provide a large amount of resources for the system of knowledge reserve and talent reserve. At the same time, it is also conducive to the spread and diffusion of green technology and further promotes the operation of the green innovation system. The implementation of the green innovation system in universities can be expressed by the following equation [20]:

$$
F_{1}=\frac{G-S g V-W}{v_{\max }-g} .
$$

Different from the enterprises and the government, the calculation of the ability to carry out the green innovation system is relatively simple, and the influence elements are few. In the equation, $F_{1}$ represents the ability of the green innovation system in universities, $G$ represents the relevant policies formulated by the government, $g$ represents the external influence elements, $V$ represents the teacher's ability, and $W$ represents the hardware environment of the university. The relationship between the faculty, the hardware environment, and the ability of the green innovation system in universities is shown in Figure 1.
It can be seen from the curve that there is a monotonic linear relationship between the faculty, hardware environment, and ability of the green innovation system in universities. The stronger the teachers and hardware capabilities of universities, the stronger the ability to implement the green innovation system described in.

Intermediaries play an important role in the current market economy under incomplete information. In the green innovation system, intermediary agencies do not participate in green innovation activities directly, but it is indispensable. The communication between enterprises, government, scientific research institutions, and other innovative bodies cannot be separated from intermediary agencies. The role of agencies in the green innovation system is shown as follows:

$$
F_{2}=\iint g^{p} F^{q} f(x, y) d_{x} d_{y}
$$

On the one hand, intermediary agencies provide services for enterprises, including information dissemination, consulting services, and financial support, so as to reduce the number of invalid transactions under the condition of incomplete information. On the other hand, intermediaries are an adhesive in the green innovation system and can well coordinate the behavior between the various green innovation subjects.

2.2. Determination of Functional Elements. The so-called system function refers to something that the green innovation system of manufacturing industry is engaged in. Researchers around the globe have conducted multiple studies on the functions of innovation systems [21-24]. Based on these studies, combined with the computer conditions, the analysis of functional elements includes the following aspects.

If there is no entrepreneur and if innovation is impossible, then the green innovation system of manufacturing will not come into being. The role of entrepreneurs is to transform new knowledge development capabilities, networks, and markets to generate and utilizes industry opportunities:

$$
g(i, j)=\frac{f(i, j)-f_{\min }}{f_{\max }-f_{\min }} .
$$

In this equation, $g(i, j)$ represents the learning mechanism function of knowledge development (learning), $f(i, j)$ represents the entrepreneur function in the green innovation system of manufacturing industry, $f_{\max }$ represents the maximum function coefficient, and $f_{\min }$ represents the minimum function coefficient.

The authors in [25] believe that the basic function of the innovation system is information exchange, i.e., knowledge diffusion. In the green innovation system, knowledge diffusion is also important in a strict R\&D environment, while the development schedule will also be influenced by norms and value changes. From this point of view, the network interaction of the green innovation system in manufacturing industry is a prerequisite for interactive learning. If it is a 
consumer producer network, then it can be seen as learning in use. Combined with equation (5), we get the knowledge diffusion function $u(i, j)$ and the relation curve with $g(i, j) / f(i, j)$, as shown in Figure 2 .

According to the curve, we can get better knowledge diffusion when the entrepreneur and learning mechanism are sound. On the contrary, when entrepreneurs or learning mechanisms are not perfect, it is difficult to obtain better knowledge diffusion. For example, the government issued a statement aimed at achieving a certain proportion of renewable energy in the next few years. The implementation of sustainable energy technology development has stimulated the flow of resources needed to promote this development. At the same time, there are exceptions because accidental exceptions may lead to a specific theme, resulting in a specific direction of change.

Resource flow that includes financial resources and human resources are important inputs for all activities in the green innovation system of manufacturing industry. Especially in biotechnology, the rich availability of biological resources is a potential element determining the success or failure of projects. It can be defined as follows:

$$
M=L-L_{0}+k A \text {. }
$$

We must create a sense of legitimacy/change resistance, and new technology must become part of the existing system or overturn it. Interested bodies often object to this creative destruction. In this way, advocating joint will become a catalyst to promote the legalization of new technologies and hinder opposition to change.

2.3. Determination of Environmental Elements. The system has the same function and its restraint and standardization. If the current system is not coordinated with the development of the green innovation system in the manufacturing industry, the development will be restricted, and the relevant departments of the government and other relevant departments should be adjusted accordingly. Therefore, in order to ensure the continuous progress and perfection of the green innovation system in the manufacturing industry, the institutional environment must be constantly changed and self-rectified to promote the smooth development of the green innovation activities of the manufacturing industry. It can be described by the following equation:

$$
H=\frac{\partial^{2} M}{\partial V \cdot \partial\left(A_{1}+A_{2}\right)} .
$$

A good market environment will play a positive role in stimulating the green innovation system of manufacturing industry. First, the market can test whether green innovation is successful. Under the conditions of the fully developed market economy, a successful new technology, which is welcomed by the consumer, will quickly occupy the monopoly position, form the technical barrier, obtain the excess profit, and not be easily imitated action of a good competition mechanism. In the market, competition and cooperation are the same. Green technology innovation in manufacturing industry has high risk and uncertainty, constantly learning, improving and self-improving, and seeking survival in the competition. The schematic diagram of the green innovation system of manufacturing industry can be expressed in Figure 3. At the same time, the correlation between hard environment element $\left(A_{1}\right)$ and soft environment coefficient $\left(A_{2}\right)$ can be reflected from the following diagram.

Social culture environment is a subtle spiritual force that indirectly affects the open mode of the green innovation system in manufacturing industry. In the green innovation system of manufacturing industry, a good social and cultural environment is conducive to the development of green innovation activities among various subjects. At the same time, it is also beneficial to the communication and study among various subjects and to realize the long-term and benign operation.

\section{Analysis of the Mechanism of Open Innovation Model Construction}

In this section, first we analyze the theory of open innovation evaluation followed by the formulation of information selection rules of the open innovation mode.

\subsection{Analysis of the Theory of Open Innovation Evolution.} In 1994, John Holland formally proposed the open innovation system theory (OST). The theory is based on the open innovation evolution perspective to analyze the origin of open innovation. The adaptability of the macrolevel is the process of investigating how the subject can present with the external knowledge and technology in the macroenvironment of the external economy and the globalization of technology. The core idea of open innovation theory is to create openness with adaptability. The basic characteristic function of its open innovation mode is shown in the following equation:

$$
\left\{\begin{array}{l}
F \frac{\partial y}{\partial x}=M U+A \frac{\partial P}{\partial x}+q S \\
M\left(\frac{\partial}{\partial t}+U \frac{\partial}{\partial x}\right)^{2} y+(q S+M U) \frac{\partial y}{\partial x}+F=0 .
\end{array}\right.
$$

In this equation, $M$ represents the return rate of the green innovation system in manufacturing industry, $F$ represents green innovation technical ability, $A$ is the return item, $U$ represents adaptive subjectivity, $x$ and $y$ represent the adaptability of the environment and individual, $q$ represents the macroreaction coefficient, and $S$ represents the microcosmic reaction coefficient.

\subsection{Formulation of the Information Selection Rules of the Open} Innovation Model. Through the integration of internal and external resources of the enterprise, the utility maximization can be obtained, and the open innovation pattern awareness maximizes the innovation performance through the integration of internal and external resources. Innovation 


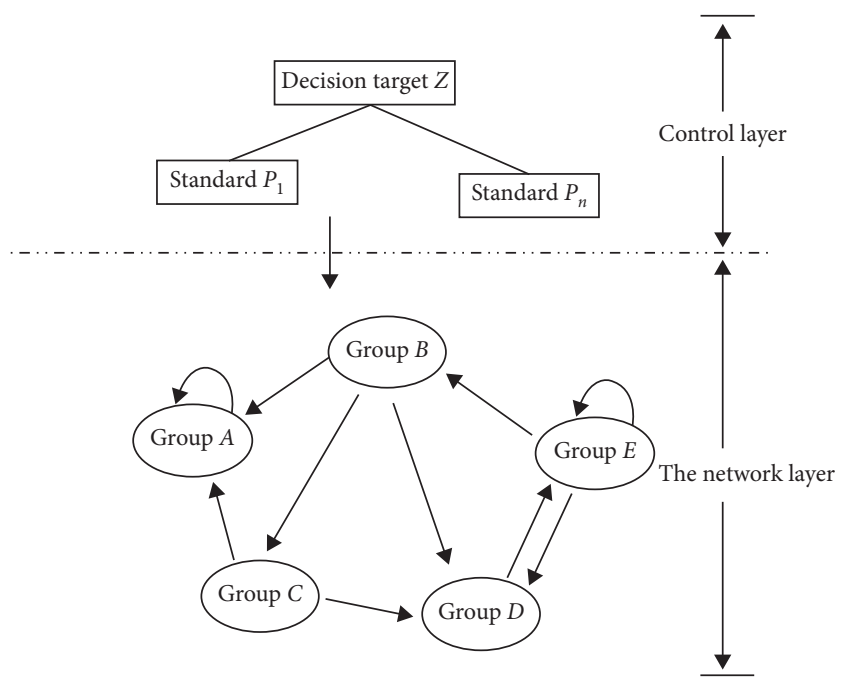

FIgURE 1: The relationship between the faculty, hardware environment, and ability of the green innovation system in universities.

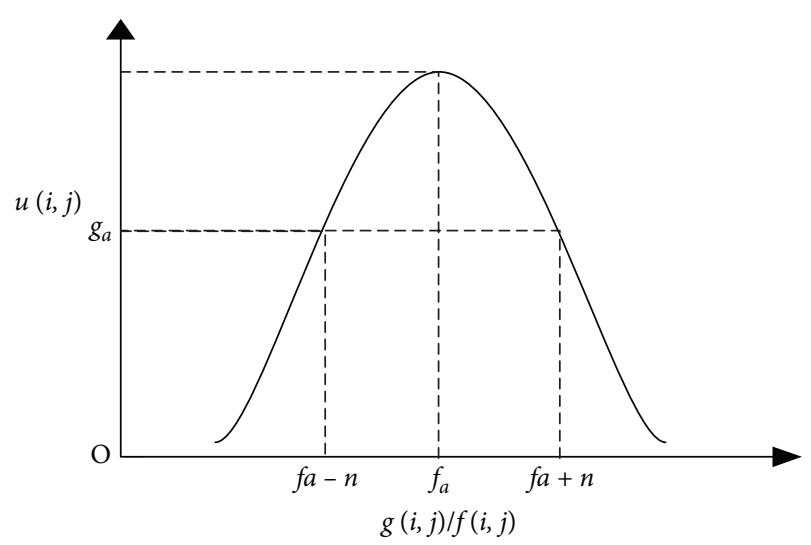

FIgURE 2: The relationship between knowledge diffusion and entrepreneurial learning mechanism.

adaptability is a rule to distinguish information through a kind of internal information. When exploring the current system information, it can judge the current form and take action. The open innovation model is also when a subject develops new technology or new product. The results are passed so that other enterprises can learn from them. It can use Figure 4 to represent the optimal selection curve of the two different subjects inside or outside. The best choice curve between the two subjects inside or outside is shown in Figure 4.

Open innovation is an innovative activity integrating knowledge innovation, technology innovation, and system innovation. In the innovation activities, the innovation elements will flow and change, especially the innovation elements such as funds, information, technology, knowledge and talents, and continuous transformation between enterprises and environment. The innovative and open characteristics of the open innovation require that the innovative subjects need to continuously improve their adaptability to meet the changes in the internal and external environment of innovation. Open innovation also has the characteristics of the green innovation system. The characteristic function can be expressed in the following equation:

$$
\left\{\begin{array}{l}
R(x)=r_{n-1} x^{n-1}+r_{n-2} x^{n-2}+\cdots+r_{1} x+r \\
C(x)=c_{n-1} x^{n-1}+c_{n-2} x^{n-2}+\cdots+c_{1} x+c \\
E(x)=e_{n-1} x^{n-1}+e_{n-2} x^{n-2}+\cdots+e_{1} x+c .
\end{array}\right.
$$

In this equation, $R(x)$ represents the knowledge innovation of open innovation, $C(x)$ represents the technological innovation of open innovation, $E(x)$ represents the system innovation of open innovation, $r$ represents knowledge innovation ability, $c$ represents system innovation ability, and $e$ represents system innovation ability.

\section{Construction of Open Innovation Model}

In this section, first we determine the operating index followed by the operation mechanism of the open innovation model.

4.1. Determination of the Operating Index. The concept of the green innovation system mainly revolves around "four characteristics and three mechanisms." Four characteristics are reflected by aggregation, nonlinearity, flow, and diversity, and the three mechanisms are through identification, internal mechanism, and building blocks. The characteristics of the subject are the process of adapting to the environment under the action of the green innovation system in order to adapt to the change of the environment. The mechanism is the lubricant and coordination agent in the process of the subject adaptation, reflecting the application process of the main whole and the external environment. Similarly, in the open innovation mode, we can find the corresponding process of how the main body and mechanism of enterprises change. The formula can be expressed as

$$
G=\frac{\partial^{2} a}{\partial \delta} \cdot \sum_{i=1}^{n} \lambda p \cdot\left(m v^{2}+o z+G_{0}\right)-G \alpha .
$$

Here, $G$ represents a unified dimensional unit, $a$ represents the overall coefficient, $\delta$ represents the integrity of 7 indicators, $\lambda$ represents aggregation, $p$ represents nonlinear, $m$ represents flow (flows), $v$ represents diversity identification, $\alpha$ represents internal model, $O$ represents building blocks, and $z$ represents diversity. The specific meaning is as follows:

(i) Aggregation: the subject is based on the similarity and commonality of $R \& D$ to gather the available bodies together through the features of "adhesion." The effect of aggregation is the mechanism of R\&D activities at different levels after a low level of screening. In the innovation model of the equipment manufacturing industry, the main body of innovation consists of a large number of interacted entities, such as enterprises, universities, scientific research institutions, government, and technical intermediaries. These bodies can form more 
advanced subjects through interaction, such as industrial alliance, industry research alliance, and official production. This can highlight the characteristics of aggregation at different levels. The aggregation formula is shown in equation (11); $\lambda$ represents aggregation, $\lambda_{0}$ represents initial aggregation, $e$ stands for R\&D similarity, and $f$ represents R\&D commonality:

$$
\lambda=p \lambda_{0}+\log \left(a^{n}+e f\right) .
$$

The main body of the equipment manufacturing system in China has the mechanism of adaptation and learning. It is not a direct purchase application and a simple imitation, but through digestion and absorption of relevant content, so as to gradually improve innovation capabilities.

(ii) Diversity: it reflects the different characteristics of the subject, and the advantages of the enterprise in a certain aspect, such as some of the automobile enterprises are good at developing the engine, display screen, and design, and the versatility is the prerequisite for the continuous evolution of the system. In China's equipment manufacturing system, each subject has his own unique technology, product, service characteristics, scientific research achievements, and scientific research expertise, which determine the diversity of different subjects. The influence function on diversity is shown in the following equation:

$$
z=\frac{\sum_{i=1}^{n}\left(a_{i}-\bar{a}\right)\left(f_{i}-\bar{f}\right) \cdot 1}{\sum_{i=1}^{n}\left(h_{i}-\bar{h}\right)} .
$$

Here, $z$ stands for diversity, $a$ stands for theme embodiment, $f$ represents relative advantages, and $h$ represents acceptance of the masses.

(iii) Tagging: tagging refers to the ability of a subject to recognize and respond from different information through its choice of diversity. It is the process of selecting valuable information in diversity, and different subjects have different tags and response mechanisms for the information obtained. In China's equipment manufacturing system, enterprises, universities, government, research institutions, and other industrial technologies are all tags; the aggregation of the various main bodies forms the different industries, enterprise groups, industry and research community, knowledge community, and so on.

(iv) Internal model: the mechanism that the main body will collect and transform the innovation source within the enterprise and innovate it. The subject is required to enter the selected innovation source into the internal structure model of the system and select the structure of the model in the innovation system. In this internal model, the innovation body can foresee the output structure obtained by the input.
For enterprises, universities, scientific research institutions, and government, they all have the foreseen mechanism and ability. If we meet the innovation pressure, we can improve the innovation ability by changing the internal structure, such as the innovation model.

(v) Building blocks: also known as the component, it is the key element in the open innovation model, such as the technical personnel of scientific research, capital, equipment, science and technology, knowledge and information, management system, and operation mechanism:

$$
O=\frac{p \sum_{i=1}^{n}\left(r_{i}-\bar{r}\right)\left(c_{i}-\bar{c}\right) \cdot 1}{\left[\sum_{i=1}^{n}\left(b_{i}-\bar{b}\right)\right]+\log \left(r^{n}+u i\right)}
$$

Here, $O$ represents building blocks, $r$ represents relevant technical personnel, $c$ represents equipment, $b$ represents funds, $n$ represents technology and technology knowledge, $u$ represents the information management system, and $i$ represents the operation mechanism.

4.2. Operation Mechanism of Open Innovation Model. The open innovation of equipment manufacturing industry includes seven elements, namely, four characteristics and three mechanisms, which are involved in the innovation system. It mainly includes the basic and core elements of the model, which can be described in an open innovation module with signs, attributes, and behavior.

(i) Logo: the characteristics of the element identification included in the innovation adaptive system are also to distinguish the signs of other enterprises because each open innovation is different from the other open innovation, and each subject has its own unique characteristics. That is to say, each open innovation has special logos in the microenvironment and macroenvironment. The initiative adaptability of open innovation is to start with identifying logos.

(ii) Property: the characteristics of diversity are included in the innovation adaptive system because open innovation is a unique symbol; in the process of stimulus response modeling, we need to consider the properties of the physical, space, and quality of the main body. The attributes in the model are the characteristics of other subjects encountered by the enterprise in the external environment. These attributes will be applied to the implementation process of the main body. It is also the basis of the decision analysis of the subject.

(iii) Behavior: that is to say, the system will finally show the process of aggregation, nonlinearity, flow, internal models, and building blocks. After determining the main body in the innovation adaptive system, the innovation results are generated by the interaction of material flow, information flow, and 


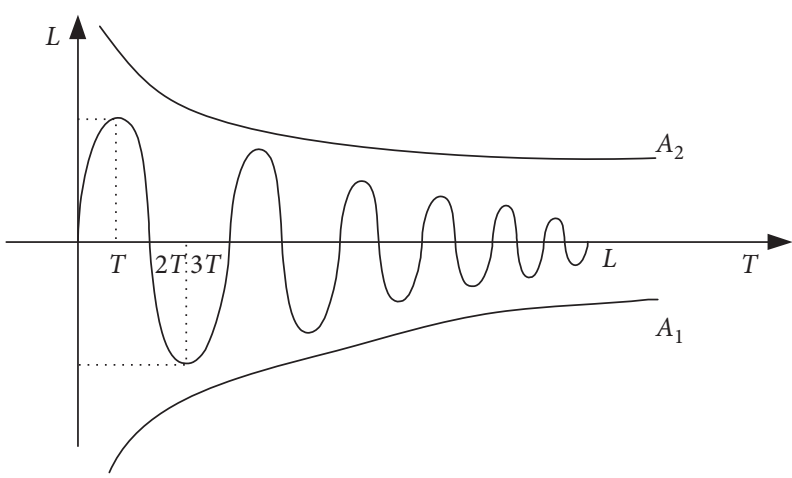

FIGURE 3: Dynamic schematic diagram of a green innovation system in the manufacturing industry.

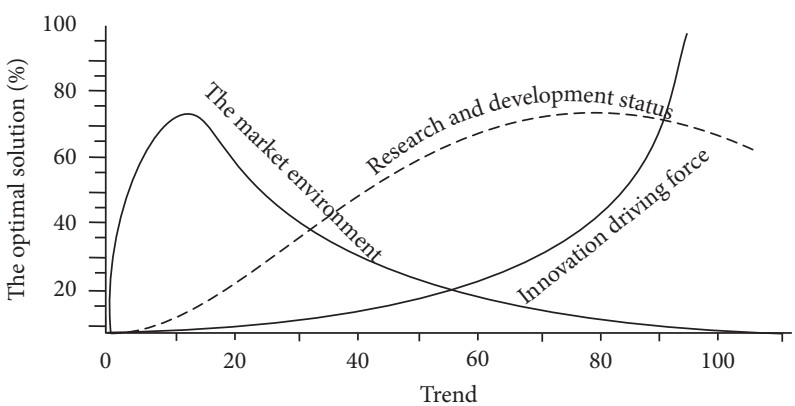

Figure 4: The best choice curve between the two subjects inside or outside.

energy flow in the mechanism of the innovation adaptive system through mutual learning. This is the process of which the main body acts, makes decisions, and adapts. That is the necessary condition for the stimulus response mode. It describes the correlation relationship, as shown in Figure 5.

The main model of the green innovation system theory is the stimulus response mechanism: this model can reflect the behavior pattern of the main body at the microlevel. The adaptive evolution of each adaptive subject requires three aspects of a detector, an effector, and an IF/THEN rule. The stimulus that the main body uses the detector to receive the external environment is also the input of relevant information, knowledge, and technology. The effector is the output of the external stimulus through a certain adaptive process. The IF/THEN rule is the process of responding to the input stimulus. In response to realistic activities, OST theory sets different rules, and different ways can be chosen for different stimuli. The open innovation mode of equipment manufacturing industry based on the stimulus response is shown in Figure 6.

On one hand, the green innovation system of manufacturing industry can optimize the market structure, improve the degree of rationalization of the industrial structure, and promote the innovation of the system. On the other hand, the green innovation system in manufacturing industry is also beneficial to the improvement of the economic level and the quality of the products. Facing the resource crisis, we made contributions to effectively implement green innovation activities for energy conservation and emission reduction.

\section{Experimental Analyses}

In order to ensure the effectiveness of the open innovation mode of the green innovation system in manufacturing industry under the Internet condition, the simulation analysis is carried out. During the test, different manufacturing industries were used as the test objects to carry out the simulation test of operational capability and analysis coverage. The different production types and scale of manufacturing are simulated.

5.1. Data Preparation. The parameter settings for the original data are shown in Table 1.

5.2. Analysis of Test Results. The operation capability and the analysis coverage simulation test are carried out only for the different manufacturing industries and the open innovation model of different innovation systems. The test curve of its operating capacity is shown in Figure 7.

In the above figure, Figure $7(a)$ is the test curve of the traditional method's running ability and Figure $7(\mathrm{~b})$ is the running ability curve of the proposed method. According to the test curve, the operation ability of the traditional method is $65 \%$, and the operation ability of the proposed method is 98.42. The open innovation mode of the green innovation system is $33.42 \%$ higher than that of the conventional model. 


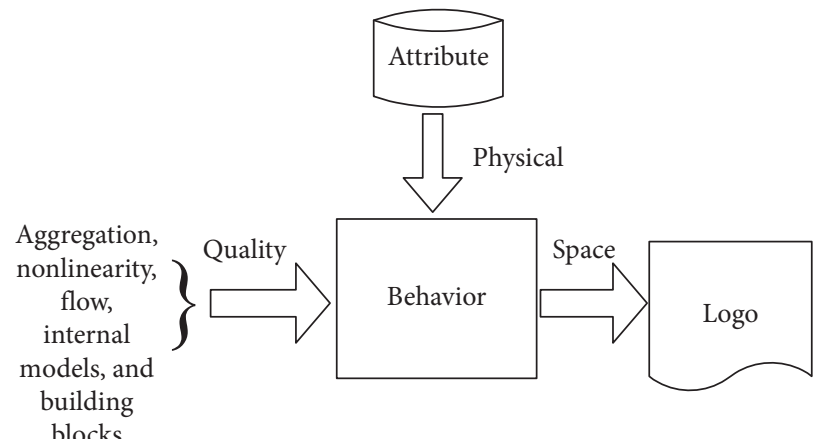

FIGURE 5: The correlation relationship.

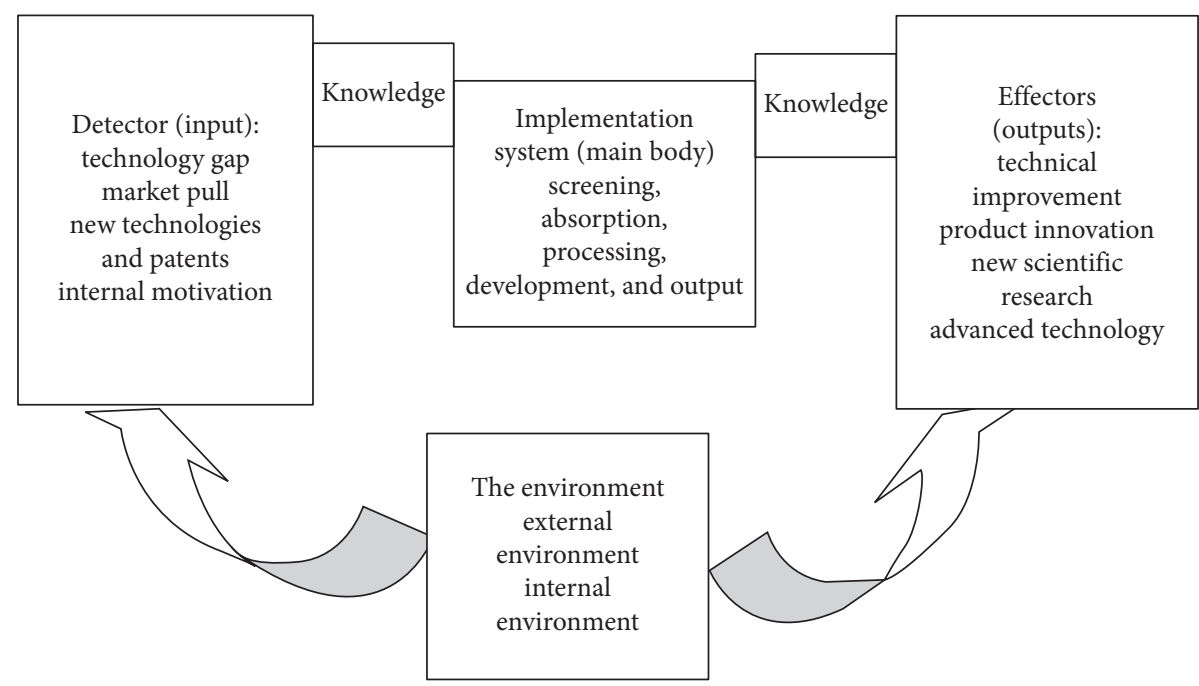

FIGURE 6: Open innovation model of equipment manufacturing industry based on the stimulus response.

TABLE 1: Test parameters' setting.

Manufacturing type

Manufacturing scale/5 million The production type

Agricultural and sideline food processing industry

$50 \quad$ Engineer to order

Manufacturing of railway, ship, aerospace, and other transportation equipment 200

Wine, drinks, and refined tea

450

650

Nonferrous metal smelting and rolling industry

Black metal smelting and rolling industry

750

Textile and clothing industry

Leather, fur, feathers and their products, and footwear

200

450

Wood processing and wood, bamboo, rattan, brown, and grass products

Manufacturing of computers, communications, and other electronic equipment

Metal products, machinery, and equipment repair

Printing and recording media reproduction

Education, industry, sports, and entertainment industries

Petroleum processing, coking, and nuclear fuel processing industries
Engineer to project

Make to order

Assemble to order

Make to stock

Repetitive Batch

Continuous

Engineer to order

Engineer to project

Make to order

Assemble to order Make to stock
At the same time, two different methods are used to analyze the coverage test. Analysis of coverage test curves is shown in Figure 8.

Figure $8(\mathrm{a})$ is the test curve of the traditional method's running ability under the low difficulty. Figure $8(\mathrm{~b})$ is the running ability curve of this method under the low difficulty. Figure $8(\mathrm{c})$ is the test curve of the traditional method running ability under the high difficulty, and Figure $8(\mathrm{~d})$ is the running ability curve of this method under the high difficulty. Through third party analysis software, the average value of the arithmetic is taken. The two methods run under different difficulty levels, and the coverage rate is not obvious. The open innovation model of the green innovation system is compared with the conventional model; the 


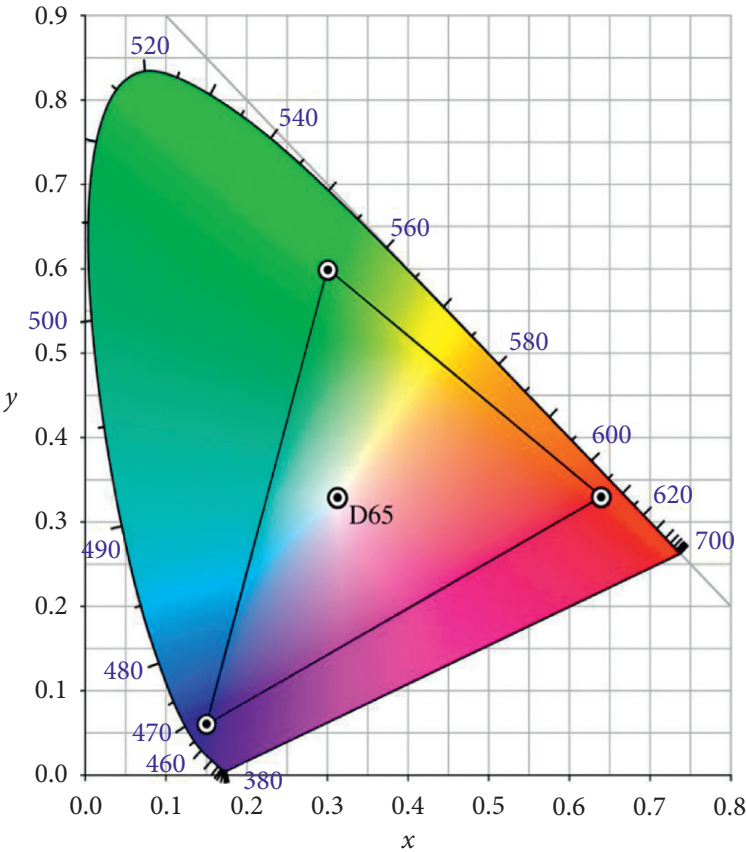

(a)

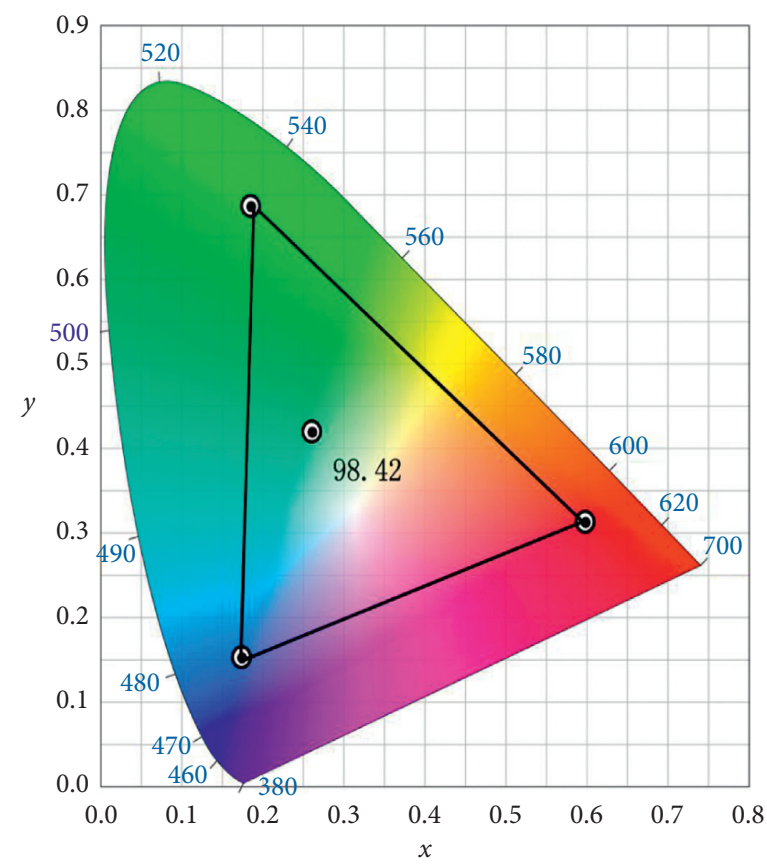

(b)

FIgURE 7: Running capacity test curve.

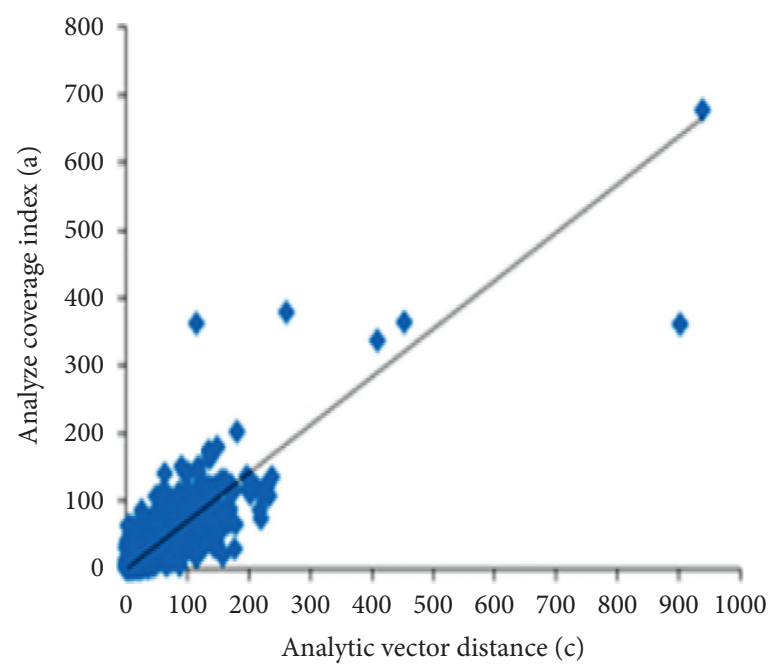

(a)

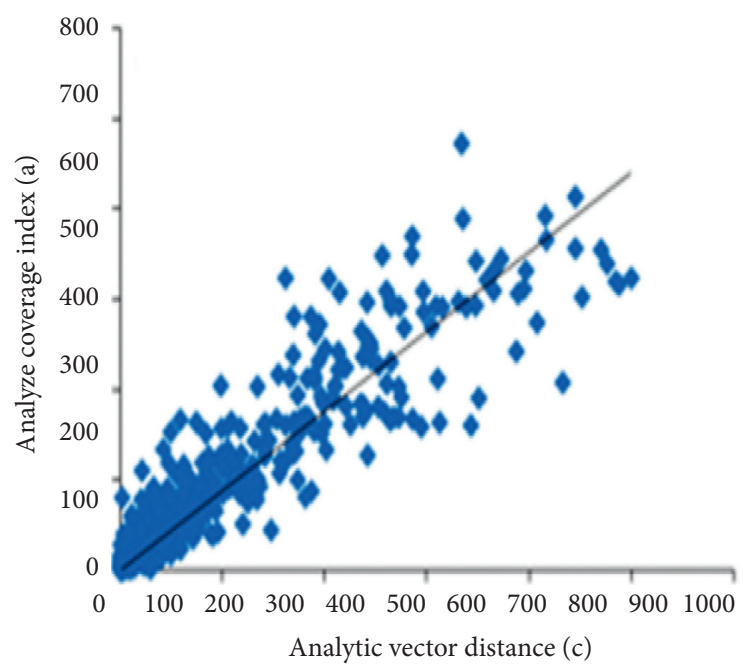

(b)

Figure 8: Continued. 


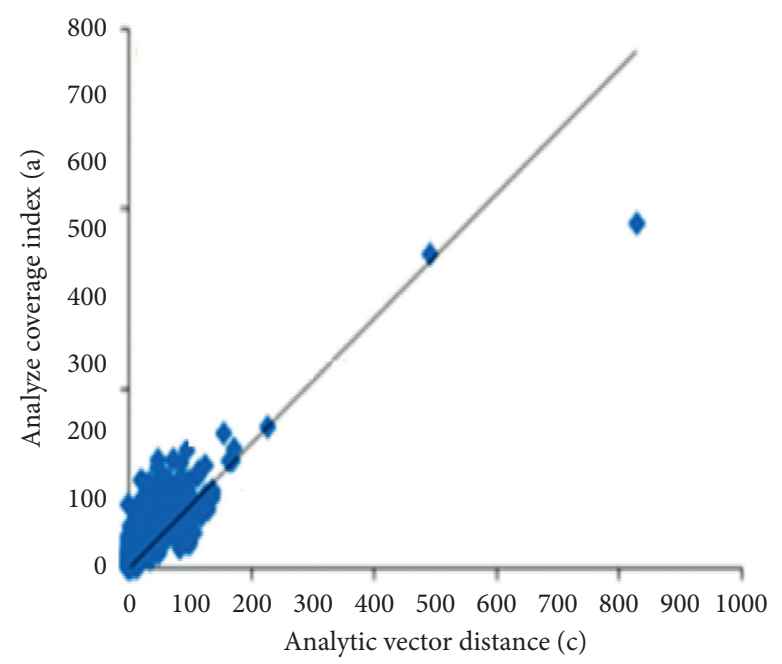

(c)

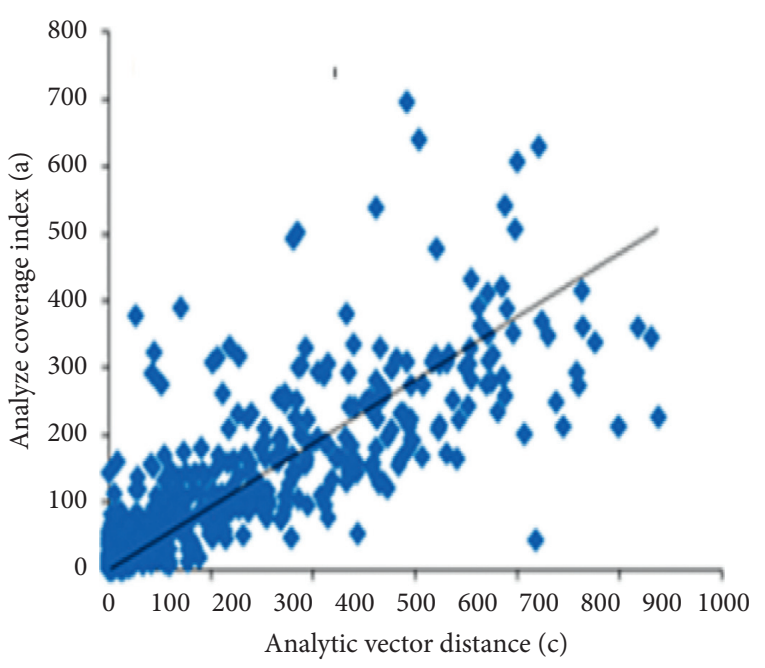

(d)

FIgURe 8: Analysis of coverage test curves.

coverage rate is raised by $54.32 \%$. It can realize the open and innovative operation of the green innovation system.

\section{Conclusion}

In this paper, an open innovation model of a green innovation system in the manufacturing industry is put forward. Its mechanism is analyzed, and the model is built to realize the objective of this paper. The influencing factors of the open innovation model based on the industrial green innovation system are clarified. Through the relevant literature research and the understanding of related concepts, the model's influencing factors, i.e., the system's participants, the openness, and the technological environment, are examined. The influence of the system participants mainly comes from the participants' innovation strength, the innovation resources owned by the participants, the number of participants, etc. The influence of openness primarily comes from the industrial green innovation system's exposure, the openness of the innovation subjects within the system, etc. The technological environment's influence mainly comes from the integration of technology and industrial production chain and the integration of technology under the environment. The understanding of these factors provides a basic reference for the classification of the open innovation model. Moreover, this paper classifies the open innovation mode, based on the industrial green innovation system, into numerous influencing factors: innovation alliance mode, investment and merger mode, resource integration mode, and open platform mode. According to the resource-based theory and life cycle theory, the selection ideas and research methods of the open innovation mode are determined.

\section{Data Availability}

The data used to support the findings of this study are available from the corresponding author upon request.

\section{Conflicts of Interest}

The authors declare that they have no conflicts of interest.

\section{References}

[1] Y. Xing and H. Li, "A simulation study on optimization and forecast of material supply demand in automobile manufacturing industry," Computer Simulation, vol. 33, no. 10, pp. 421-424, 2016.

[2] P. Lu, Y. Mou, and Z. Zhang, "Study on the detection method of unreachable function call path in complex system," Computer Simulation, vol. 33, no. 9, pp. 426-430, 2016.

[3] Y. Xu, G. Y. Zhang, and D. Sheng, "Research on the growth model of scientific and technological innovation talents based on hierarchical clustering," Computer Simulation, vol. 34, no. 8, pp. 351-355, 2017.

[4] H. H. Chen, S. Chen, and Y. Lan, "Attaining a sustainable competitive advantage in the smart grid industry of China using suitable open innovation intermediaries," Renewable \& Sustainable Energy Reviews, vol. 62, pp. 1083-1091, 2016.

[5] H. K. Jin, S. Kim, and K. Kim, "The role of learning capability in market-oriented firms in the context of open innovationbased technology acquisition: empirical evidence from the Korean manufacturing sector," International Journal of Technology Management, vol. 70, no. 2-3, p. 135, 2016.

[6] M. Usman, M. A. Jan, X. He, and J. Chen, "A survey on big multimedia data processing and management in smart cities," ACM Computing Surveys (CSUR), vol. 52, no. 3, pp. 1-29, 2019.

[7] G. Wang, X. Tian, Y. Hu et al., "Manufacturing process innovation-oriented knowledge evaluation using MCDM and fuzzy linguistic computing in an open innovation environment," Sustainability, vol. 9, no. 9, pp. 1-19, 2017.

[8] S. O. Shim and K. B. Park, "Technology for production scheduling of jobs for open innovation and sustainability with fixed processing property on parallel machines," Sustainability, vol. 8, no. 9, p. 904, 2016.

[9] S. Ortega-Requena and S. Rebouillat, "ChemInform abstract: bigger data open innovation: potential applications of valueadded products from milk and sustainable valorization of by- 
products from the dairy industry," Green Chemistry, vol. 47, no. 7, pp. 5100-5113, 2016.

[10] A. Zobel, "Benefiting from open innovation: a multidimensional model of absorptive capacity," Journal of Product Innovation Management, vol. 34, no. 3, pp. 269-288, 2017.

[11] X. Zhu, M. C. Dong, J. Gu et al., "How do informal ties drive open innovation? the contingency role of market dynamism," IEEE Transactions on Engineering Management, vol. 64, no. 2, pp. 208-219, 2017.

[12] B. Yuan and Q. Xiang, "Environmental regulation, industrial innovation and green development of Chinese manufacturing: based on an extended CDM model," Journal of Cleaner Production, vol. 176, pp. 895-908, 2018.

[13] N. Nilsson and T. Minssen, "Unlocking the full potential of open innovation in the life sciences through a classification system," Drug Discovery Today, vol. 23, no. 4, pp. 771-775, 2018.

[14] J. Hou, H. Chen, and J. Xu, "External knowledge sourcing and green innovation growth with environmental and energy regulations: evidence from manufacturing in China," Sustainability, vol. 9, no. 3, p. 342, 2017.

[15] N. Miglietta, E. Battisti, and F. Campanella, "Value maximization and open innovation in food and beverage industry: evidence from US market," British Food Journal, vol. 119, no. 11, pp. 2477-2492, 2017.

[16] J. L. Wadin, K. Ahlgren, and L. Bengtsson, "Joint business model innovation for sustainable transformation of industries-a large multinational utility in alliance with a small solar energy company," Journal of Cleaner Production, vol. 160, pp. 139-150, 2017.

[17] M. A. Jan, W. Zhang, M. Usman, Z. Tan, F. Khan, and E. Luo, "SmartEdge: an end-to-end encryption framework for an edge-enabled smart city application," Journal of Network and Computer Applications, vol. 137, pp. 1-10, 2019.

[18] Z. Feng and W. Chen, "Environmental regulation, green innovation, and industrial green development: an empirical analysis based on the spatial durbin model," Sustainability, vol. 10 , no. 1, p. 223, 2018.

[19] A. Akbar, M. Ibrar, M. A. Jan, A. K. Bashir, and L. Wang, "SDN-enabled adaptive and reliable communication in IoTfog environment using machine learning and multi-objective optimization," IEEE Internet of Things Journal, vol. 8, no. 5, pp. 3057-3065, 2020.

[20] E. A. Severo, J. C. F. D. Guimarães, and E. C. H. Dorion, "Cleaner production and environmental management as sustainable product innovation antecedents: a survey in Brazilian industries," Journal of Cleaner Production, vol. 142, no. 1, pp. 87-97, 2018.

[21] F. Khan, A. ur Rehman, and M. A. Jan, "A secured and reliable communication scheme in cognitive hybrid ARQ-aided smart city," Computers \& Electrical Engineering, vol. 81, pp. 291-302, 2020.

[22] S. Lin, J. Sun, D. Marinova et al., "Evaluation of the green technology innovation efficiency of China's manufacturing industries: DEA window analysis with ideal window width," Technology Analysis \& Strategic Management, vol. 30, no. 1, pp. 1-16, 2018.

[23] X. Xie, J. Huo, G. Qi et al., "Green process innovation and financial performance in emerging economies: moderating effects of absorptive capacity and green subsidies," IEEE Transactions on Engineering Management, vol. 63, no. 1, pp. 101-112, 2016.

[24] M. Usman, M. A. Jan, A. Jolfaei, M. Xu, X. He, and J. Chen, “A distributed and anonymous data collection framework based on multilevel edge computing architecture," IEEE Transactions on Industrial Informatics, vol. 16, no. 9, pp. 6114-6123, 2019.

[25] Y. Guo, X. Xia, S. Zhang et al., "Environmental regulation, government R\&D funding and green technology innovation: evidence from China provincial data," Sustainability, vol. 51, no. 4, pp. 1563-2157, 2017. 